Furthermore, additional chain elongation before the $\omega$-oxidation step in the biosynthesis of these methyl-branched chain dicarboxylic acids would be expected to lead to methylazeleic and methylsebacic acids.

Finally, condensation of propionyl-CoA with malonyl-CoA and chain elongation by fatty acid synthetase followed by $\omega-$ oxidation would yield straight chain odd-numbered dicarboxylic acids. The occurrence of $\mathrm{C}_{15}-\mathrm{C}_{17}$ straight chain fatty acids has been reported in hepatic (9) and erythrocyte (7) fat of two patients with propionic acidemia $(7,9)$ and in the glycerolipids of the nervous system of a patient with methylmalonic acidemia (12). These studies on the identification and quantitation of methylbranched and straight chain dicarboxylic acids in amniotic fluid and urine in propionic and methylmalonic acidemia may contribute to explanations of the abnormal biochemistry of these disorders and to better understanding of the mechanisms of clinical illness.

Acknowledgments. We thank Dr. O. W. Jones for providing normal amniotic fluids and the many physicians who sent amniotic fluids from pregnancies at risk for the organic acidurias. We thank Dr. S. G. Kahler and Dr. Mace for providing the urine of the patients with propionic acidemia and methylmalonic acidemia, respectively.

\section{REFERENCES}

1. Allen RJ, Hansch DB, Wu HLC 1982 Hypocarnitinaemia in disorders of organic acid metabolism. Lancet 2:500

2. Buchanan PD, Kahler SG, Sweetman L, Nyhan WL 1980 Pitfalls in the prenatal diagnosis of propionic acidemia. Clin Genet 18:177

3. Chalmers RA, Lawson AM 1982 Organic Acids in Man. Chapman and Hall, London
4. Duran M, Gompertz D, Bruinvis L, Ketting D, Wadman SK 1978 The variability of metabolite excretion in propionic acidemia. Clin Chim Acta $82: 93$

5. Furniss BS, Hannaford AJ, Rogers V, Smith PWG, Tatchell AR (eds) 1978 Vogel's Textbook of Practical Organic Chemistry, ed 4. Longman, London, pp $510-511$

6. Furniss BS, Hannaford AJ, Rogers V, Smith PWG, Tatchell AR (eds) 1978 Vogel's Textbook of Practical Organic Chemistry, ed 4. Longman, London, pp 94-96, 485-488

7. Gompertz D, Bau DCK, Storrs CN, Peters TJ, Huges EA 1970 Localisation of enzymic defect in propionicacidaemia. Lancet 1:1140

8. Goodman SI, Markey SP 1981 Diagnosis of Organic Acidemias by Gas Chromatography-Mass Spectrometry. Alan R. Liss Inc, New York

9. Hommes FA, Kuipers JRG, Elema JD, Jansen JF, Jonxis JHP 1968 Propionicacidemia, a new inborn error of metabolism. Pediatr Res 2:519

10. Jakobs C, Sweetman L, Wadman SK, Duran M, Saudubray JM, Nyhan WL 1984 Prenatal diagnosis of glutaric aciduria type II by direct chemical analysis of dicarboxylic acids in amniotic fluid. Eur J Pediatr 141:153

11. Jakobs C 1983 Contribution to the prenatal diagnosis of inherited metabolic disorders: analysis of metabolites in amniotic fluid. Doctoral thesis, Rijksuniversiteit, Utrecht

12. Kishimoto Y, Williams M, Hugo WM, Hignite C, Biemann K 1973 Branchedchain and odd-numbered fatty acids and aldehydes in the nervous system of a patient with deranged vitamin $B_{12}$ metabolism. J Lipid Res 14:69

13. Markey SP, Urban WG, Levine SP (eds) 1974 Mass spectra of compounds of biological interest, vol II, part 1. Atomic Energy Commission, Office of Information Services, Technical Information Center, Oak Ridge, TN

14. Roe CR, Bohan TP 1982 L-Carnitine therapy in propionic acidemia. Lancet $1: 1411$

15. Pettersen JE, Stokke O 1973 Branched short-chain dicarboxylic acids in human urine. Biochim Biophys Acta 304:316

16. Sweetman L, Nayior G, Ladner T, Holm J, Nyhan WL, Hornbeck C, Griffith J, Morch L, Brandange S, Gruenke L, Craig JC 1982 Prenatal diagnosis of propionic and methylmalonic acidemia by stable isotope dilution analysis of methylcitric and methylmalonic acids in amniotic fluids. In: Schmidt $\mathrm{HL}$, Förstel H, Heinzinger K (eds) Stable Isotopes. Elsevier Scientific, Amsterdam

17. Truscott RJW, Pullin C, Halpern B, Hammond J, Haan E, Danks DM 1979 The identification of 3-keto-2-methylvaleric acid and 3-hydroxy-2-methylvaleric acid in a patient with propionic acidemia. Biomed Mass Spectrom $6: 294$

\title{
Glucocorticoids Preferentially Increase Fetal Alveolar $\beta$-Adrenoreceptors: Autoradiographic Evidence
}

\author{
PETER BARNES, ${ }^{1}$ MARK JACOBS, ${ }^{2}$ AND JAMES M. ROBERTS ${ }^{3}$ \\ Department of Obstetrics, Gynecology, and Reproductive Sciences and Cardiovascular Research Institute, \\ University of California, San Francisco, California 94143
}

\begin{abstract}
To localize fetal rabbit lung $\beta$-adrenoreceptors before and after glucocorticoid treatment, light microscopic autoradiography was performed with the reversible radiolabeled $\beta$-adrenergic antagonist, $\left[{ }^{3} \mathrm{H}\right]$ dihydroalpreno-
\end{abstract}

Received April 27, 1983; accepted November 29, 1983.

Reprint requests may be addressed to James M. Roberts, M.D., Department of Obstetrics, Gynecology, and Reproductive Sciences, HSE 1453, University of California, San Francisco, San Francisco, CA 94143.

This work was supported by National Institutes of Health Grant HUHD 24056.

${ }^{1}$ Current address: Department of Medicine, Royal Postgraduate Medical School, Hammersmith Hospital, London W12 OHS, England.

${ }^{2}$ Recipient of National Institutes of Health Training Grant HD07162. Current address: Department of Obstetrics, Gynecology and Reproductive Sciences, HSE 1462, University of California, San Francisco, San Francisco, CA 94143.

${ }^{3}$ Recipient of National Institutes of Health Career Development Award HD00267. lol, on day 26 of gestation. Autoradiograms of adult lung and fetal myocardium were also prepared. Examination of these autoradiograms showed densely labeled airways, alveoli, and myocardium. Specific labeling, defined as that prevented by incubation with l-propranolol $(1 \mu \mathrm{M})$, was $90 \%$. Analysis of grain counts in the fetus showed that airways were more densely labeled than alveoli $(p<0.001)$, labeling was increased by treatment $(p<0.001)$ and treatment increased alveolar $(p<0.002)$ but not airway labeling. Adult lungs were much more densely labeled than fetal, and fetal myocardial labeling was not altered by treatment. Adult untreated lung showed the same pattern as fetal untreated lung with airways being more densely labeled than alveoli $(p<0.001)$. To validate estimates of 
relative $\beta$-adrenoreceptor concentration derived from autoradiograms, comparisons to determinations of $\beta$-receptor concentration from scintillation counting of lung section digests and from previously performed radioligand binding studies, using membranes prepared from whole lung homogenates, were made. There is excellent agreement between estimates of relative receptor concentration and specific binding derived from the counting of autographic grains and both scintillation counting of lung section digests and previously performed radioligand binding of lung particulate. In all preparations, specific binding was $(\mathbf{9 0 \%})$, increased with glucocorticoid treatment in fetal lung (50$100 \%$ ), was greater in concentration in adult compared to fetal lung (7-10-fold), and did not increase in fetal myocardium with treatment. We conclude that $\beta$-adrenoreceptors can be localized within the fetal lung with this autoradiographic method and that airways and alveoli contain $\beta$-adrenoreceptors, with airways containing more than alveoli in both fetal and adult lung. Also, there is a preferential increase in fetal alveolar $\beta$-adrenoreceptors after glucocorticoid treatment. This increase is not present in either airway or myocardial $\beta$-adrenoreceptors and is consistent with the known maturational effect of glucocorticoid treatment on fetal alveolar function. (Pediatr Res 18:1191-1194, 1984)

\section{Abbreviation}

DHA, dihydroalprenolol

Glucocorticoids have been shown to accelerate fetal lung devlopment in humans and experimental animals by both direct and indirect effects (2). One such an indirect effect may be to increase $\beta$-adrenergic sensitivity of the fetal lung. Previously, our laboratory and others have demonstrated that in membrane particulate prepared from fetal rabbit lung homogenate there is an increase in $\beta$-adrenoreceptor concentration during gestation $(6,8,12,15)$ which is temporally related to increasing fetal free plasma glucocorticoid concentration (11). This increase in $\beta$ adrenoreceptor concentration can be precociously produced in the fetus by administration of glucocorticoid to the pregnant doe (6). It is known that $\beta$-adrenergic stimulation of the fetal lung activates important alveolar functions necessary for the adaptation of that organ to function in its air-breathing role. These functions include the resorption of alveolar fluid (14) and the synthesis and release of surface active material (9). Also, during gestation there is an increase in the responsiveness of the fetal lung to stimulation by $\beta$-adrenergic agents (9) which may be explained by increased lung $\beta$-adrenoreceptor concentration. Because the lung is a structurally complex organ, changes in $\beta$ adrenoreceptor concentration previously described in lung homogenates might not reflect changes in alveolar $\beta$-adrenoreceptors which mediate neonatal lung adaptations. To localize $\beta$ adrenoreceptors in the fetal lung and to discriminate changes in their concentration in different lung structures after glucocorticoid treatment, we performed autoradiography of fetal rabbit lung sections with the reversible $\beta$-adrenergic antagonist $\left[{ }^{3} \mathrm{H}\right]$ dihydroalprenolol.

\section{MATERIALS AND METHODS}

Time-bred pregnant New Zealand White rabbits were obtained from LIT, Inc., Billings, MT, DHA ( $23 \mathrm{Ci} / \mathrm{mmol})$ was from New England Nuclear Corporation, Boston, MA, and other reagents and chemicals were from commercial sources. Fetal rabbits, either control or those exposed for $24 \mathrm{~h}$ to $\beta$-methasone $(0.17$ $\mathrm{mg} / \mathrm{kg}$; Celestone Soluspan, Schering Inc., Kennelworth, $\mathrm{NJ}$ ) by maternal intramuscular injection, were delivered by hysterotomy and sacrificed by cooling on ice for 7-10 min at day 26 of gestation. The fetal trachea was exposed, a plastic catheter was placed in its lumen, and $1 \mathrm{ml}$ of a $30 \%$ solution of cryostat imbedding medium (OCT Compound Ames Co., Elkhart, IN) was injected to preserve lung architecture. Fetal lungs were then immediately dissected free from the thorax and quick frozen in liquid nitrogen. Cryostat sections $8-\mu \mathrm{m}$ thick of lung and heart were mounted on gelatin-coated glass slides $(3,16)$. Sections from control adult rabbit lungs were similarly prepared. These slides, containing two to four sections each of inflated lung were incubated in $50 \mathrm{mM}$ Tris- $\mathrm{HCl}$ buffer, $\mathrm{pH} 7.4$, with $1.7 \mathrm{nM}$ DHA at $25^{\circ} \mathrm{C}$ for $20 \mathrm{~min}$. This concentration of DHA, approximately equal to the dissociation constant of DHA for fetal lung $\beta$ adrenoreceptors (6) will occupy approximately one-half of these receptors. Bound DHA was separated from free by washing in a bath of $50 \mathrm{mM}$ Tris- $\mathrm{HCl}$ buffer at $4^{\circ} \mathrm{C}$ for $10 \mathrm{~min}$ with two gentle agitations. In preliminary experiments with adult lung, this reduced nonspecific binding without decreasing specific binding (3). Drying was accomplished with compressed air at $4^{\circ} \mathrm{C}$ to minimize off-diffusion of bound radioligand. Adjacent sections were incubated similarly but with 1 -propranolol at $1 \mu \mathrm{M}$, which is approximately 100 times the inhibition constant of 1-propranolol for stereoselective DHA binding in whole lung membrane particulates (7). Nonspecific binding was defined as binding of DHA not prevented by $1 \mu \mathrm{M} 1$-propranolol. In previous experiments with fetal lung particulate, we found that at these concentrations of DHA and 1-propranolol, binding of DHA competed by 1-propranolol was virtually all $(>96 \%)$ from a high affinity stereoselective DHA-binding site. To determine optimum incubation conditions, relative receptor concentrations, and the proportion of specific binding, incubated sections from each group were removed from the slides, placed in tissue solvent (Protosol, New England Nuclear) for $12 \mathrm{~h}$ and counted by scintillation photometry at $52 \%$ efficiency. Vials containing scintillant (Hydroflor, New England Nuclear) and Protosol were weighed before and after tissue was added to determine tissue wet weight. Other glass-mounted lung sections were apposed with dry emulsioncoated glass coverslips and stored at $4^{\circ} \mathrm{C}$ for $10-12$ weeks. Coverslips were developed (D 19, Kodak) and tissue sections were stained with $2 \%$ cresyl violet.

Although the resolution of this technique does not allow localization of grains to different cell types, the specific grain counts in different lung areas could be determined by counting total autoradiographic grains in each area and subtracting nonspecific grain counts in the same area of adjacent sections. Counts were performed in lung areas corresponding to airway alveoli, and myocardium. Three areas of alveoli, airway, and myocardium were counted in three sections each of two fetuses in control and two fetuses in treated groups. Similarly, grain counts were performed from autoradiograms obtained from two adult animals. Data analysis was by analysis of variance for fetal lung grain counts and by $t$ test for adult lung and fetal myocardial grain counts. Dark field photomicrographs were made from emulsion-coated coverslips and bright field photomicrographs from stained lung sections immediately beneath the coverslips.

\section{RESULTS}

Specific DHA binding to fetal and adult lung sections $(1.7 \mathrm{nM}$ DHA with or without $1 \mu \mathrm{M} 1$-propranolol as described in "Materials and Methods") quantitated by scintillation photometry of lung section digests showed a significant increase in DHA binding of treated versus control lung sections $(3.2 \pm 0.6 \mathrm{fmol} / \mathrm{mg}$ wet weight versus $1.7 \pm 0.5 \mathrm{fmol} / \mathrm{mg}$ wet weight; $n=4 ; p<0.01$ by unpaired $t$ test). Scintillation counting of adult lung sections showed specific DHA binding (11.6 fmol/mg wet weight), seven times that present in the control fetal preparation. Light microscopy of the autoradiograms showed grains labeling airways, alveoli (Fig. 1), and heart (not shown). Two-way analysis of variance of fetal lung section grain counts (Table 1) showed 


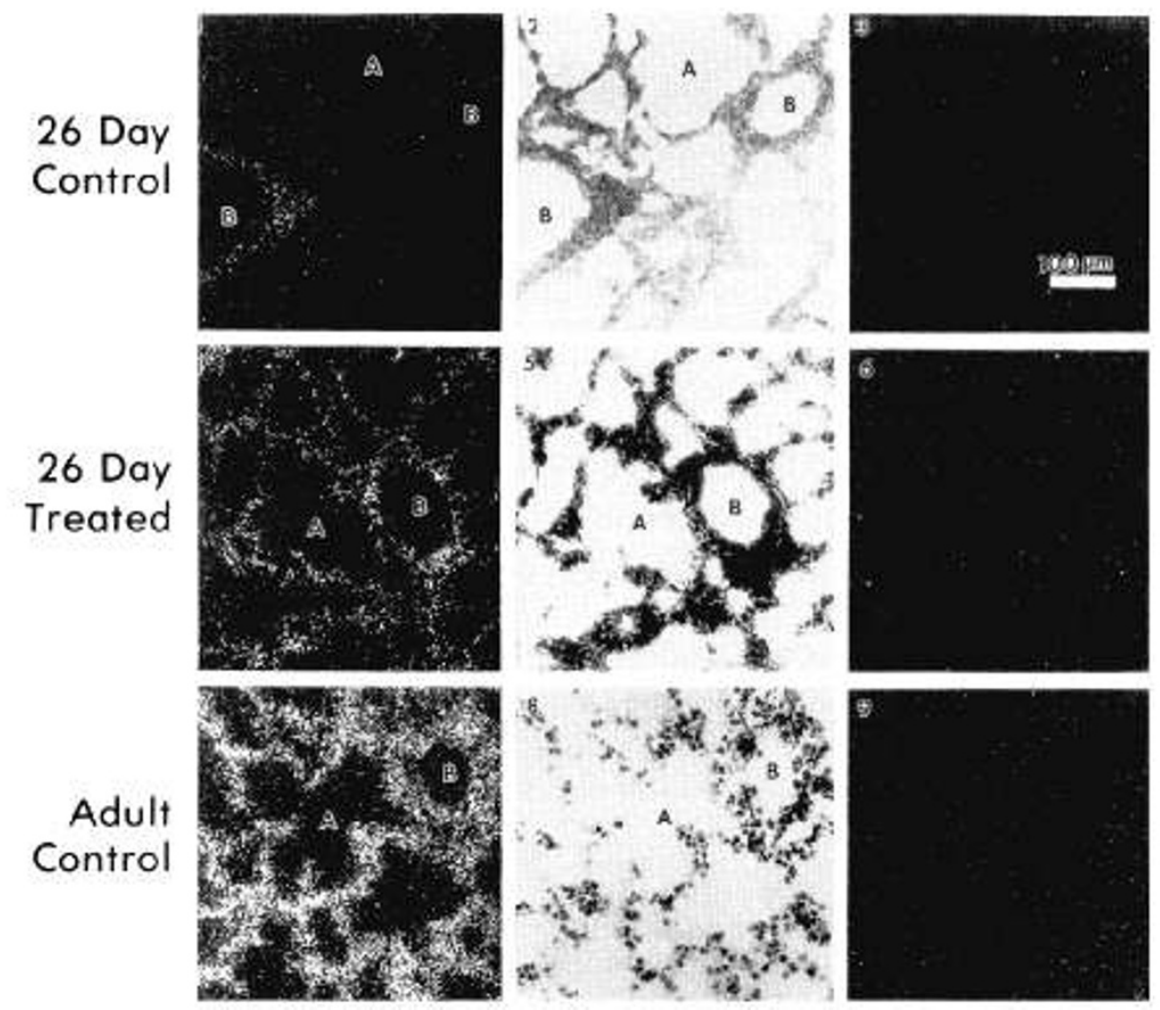

Fig. 1. Autoradiograms of DHA binding to sections of fetal and adult rabbit lung. 1-3, 25-day control fetal rabbit lung: 1 , dark field photomicrograph of autoradiogram; 2 , bright field photomicrograph of the lung section beneath $l$, showing labeling of a bronchiole $(B)$ and lesser labeling of alveoli $(A) ; 3$, dark field photomicrograph of an autoradiogram showing nonspecific labeling in the presence of $1 \mu \mathrm{m} 1$-propranolol in the same lung area of an adjacent section. 4-6, 25-day glucocorticoid fetal rabbit lung: 4, dark field; 5, bright field; and 6, nonspecific dark field photomicrographs showing an increase in alveolar labeling compared to control lungs. 7-9, adult control rabbit lung: 7, dark field; 8 , bright field; and 9 , nonspecific dark field photomicrographs showing dense labeling of both bronchioles and alveoli.

Table 1. Specific autoradiographic grain counts of $\left.{ }^{3} \mathrm{H}\right]$ dihydroalprenolol binding to sections of fetal and adult rabbit lung*

\begin{tabular}{ccc}
\hline & \multicolumn{2}{c}{ Specific grain counts $/ 1000 \mu \mathrm{m}^{2}$} \\
\cline { 2 - 3 } & \multicolumn{1}{c}{ Control } & Steroid treated \\
\hline 26-day fetal & $18.5 \pm 3.8$ & $39.2 \pm 8.5$ \\
Alveoli & $43.4 \pm 7.2$ & $54.2 \pm 6.8$ \\
Airways & $61.2 \pm 10.5$ & $56.7 \pm 10.3$ \\
Heart & & \\
Adult & $162.7 \pm 27.5$ & \\
Alveoli & $228.7 \pm 23.5$ & \\
Airways &
\end{tabular}

* Data are the means $\pm \mathrm{SD}$ of three areas from three separate slides in two animals. Two-way analysis of variance showed, in fetal lung, a significant effect of treatment $(p<0.001$, treated labeling greater than control), location ( $p<0.001$, airway labeling greater than alveolar), and a significant combined effect of treatment and location $(p<0.002$, alveolar but not airway labeling increased by treatment). Unpaired Student's $t$ test showed no difference after treatment in myocardial labeling $(p=0.6)$ and airway labeling greater than alveolar in adult $(p$ $<0.001)$.

significant effects of treatment and location and a significant combined effect of treatment on location for alveolae but not airways. Thus, treatment increased total labeling, airway labeling was greater than alveolar, and treatment increased alveolar but not airway labeling. By contrast, there was no increased specific labeling of myocardium with treatment (Table 1). Control adult lung which was very densely labeled (Fig. 1), had the same pattern as fetal lung, with airways more densely labeled than alveoli (Table 1).

\section{DISCUSSION}

$\left[{ }^{3} \mathrm{H}\right]$ Dihydroalprenolol has been shown in studies using membrane particulate from whole rabbit lung $(6,8,12,15)$ and in lung sections of adult ferret (3) to bind saturably, with high affinity and stereoselectively to lung $\beta$-adrenoreceptors. While it is difficult to precisely estimate $\beta$-receptor concentration using autoradiographic technique, in these experiments there is excellent agreement between specific grain counts and determination of $\beta$-receptor concentration obtained by other means. The estimate of increased lung $\beta$-receptor concentration after glucocorticoid treatment in the fetus using this autoradiographic method agrees with scintillation counting of fetal lung section digests; an increase of approximately $60-80 \%$. Additionally, we have reported previously that membrane particulates prepared from fetal lung after glucocorticoid treatment show a similar increase in $\beta$-adrenoreceptor concentration (6). The lack of increased specific labeling of myocardium in this autoradiographic study parallels the unchanged concentration of myocardial $\beta$-receptors prepared from membrane particulates of fetal rabbit heart after glucocorticoid treatment (6). Furthermore, the much greater specific autoradiographic labeling of adult lung sections compared to fetal lung sections is in excellent agreement with the 7 fold greater concentration determined by scintillation counting of adult lung section digests and by prior determinations of $\beta$ receptor concentration in lung membrane particulate prepared from adult lungs $(6,8)$. The estimate of specific binding of approximately $90 \%$ derived by subtracting grains counted in the presence of 1-propranolol from total grains in the same lung area in adjacent sections with this autoradiographic technique agrees well with determinations of specific binding using scintillation counting of lung section digests and those using membrane particulate prepared from whole rabbit lung. Thus, the estimation of relative $\beta$-receptor concentration by the technique of grain counting appears to be valid. 
Glucucorticoids have many effects on the structure, function, and biochemical constitution of the fetal lung $(2,13)$. Glucocorticoid treatment reduces neonatal respiratory problems in humans and in other mammals delivered prematurely $(1,10)$. Although this therapy reduces neonatal respiratory morbidity, the molecular basis by which it improves alveolar function is as yet unclear. While glucocorticoids increase the synthesis of surface active material by type II alveolar cells (5), there is evidence that surface active material, necessary for alveolar stability, may not appear in a functional form in the alveolus without $\beta$ adrenergic stimulation $(4,7)$. Because glucocorticoids also act to increase $\beta$-receptor concentration, and because the stimulation of lung $\beta$-receptors activate important alveolar functions, a major glucocorticoid action to enhance alveolar function may be through an indirect effect on alveolar $\beta$-adrenergic receptor concentration. An increase in $\beta$-adrenergic concentration in the alveolus may be responsible for the enhanced alveolar responsiveness to $\beta$-adrenergic stimulation which has been shown to occur during gestation (9). It was unclear from earlier studies of whole lung homogenate whether the increase in $\beta$-adrenergic receptors seen near term or after glucocorticoid treatment reflected an increase in the functionally important $\beta$-adrenoreceptors, those in the alveolus. Morphologic studies alone cannot directly link increased alveolar $\beta$-receptor concentration to enhanced alveolar $\beta$-adrenergic sensitivity. However, the demonstration of increased alveolar $\beta$-receptor concentration after glucocorticoid treatment could provide an important link between glucocorticoid treatment and enhanced fetal lung maturity. These autoradiographic data clearly show that there is a preferential increase in fetal alveolar $\beta$-receptors after glucocorticoid treatment; airway and myocardial $\beta$-receptors are not increased. Although airways and alveoli contain many $\beta$-adrenoreceptors, their concentration in airways is greater in both fetal and adult lung. However, the large contribution of alveolar membranes to whole lung membrane particulate implies that the alveolus is the primary source of $\beta$-receptors in whole lung membrane particulate. Thus, prior studies using membrane particulate prepared from whole lung homogenate, which demonstrated increased lung $\beta$-receptor concentration after glucocorticoid treatment, reflected increased alveolar $\beta$-receptor concentration. The mech- anism by which glucocorticoids increase the concentration of some populations of fetal $\beta$-receptors and not others is not known. However, it is clear from these preliminary studies that this differential action has both organ-specific, lung versus heart, and tissue-specific, alveoli versus airway, components.

\section{REFERENCES}

1. Avery ME 1975 Pharmacologic approaches to the acceleration of fetal lung maturation. Br Med Bull 31:13

2. Ballard PL 1982 Hormonal aspects of fetal lung development. In: Farrell PM (ed) Lung Development, Biological and Clinical Perspectives, Vol II, pp 205-245. Academic Press, New York

3. Barnes PJ, Basbaum CB, Nadel JA, Roberts JM 1982 Localization of $\beta$ adrenoceptors in mammalian lung by light microscopic autoradiography. Nature 299:444

4. Brown LAS, Longmore WJ 1982 Adrenergic and cholinergic regulation of lung surfactant secretion in the isolated perfused rat lung in the alveolar type II cells in culture. $\mathrm{J}$ Biol Chem 256:66

5. Breiher A, Benson BJ, Williams MC, Mason RJ, Ballard PL 1977 Corticosteroid induction of phosphatidic acid phosphatase in fetal rabbit lung. Biochem Biophys Res Commun 77:883

6. Cheng JB, Goldfien A, Ballard PL, Roberts JM 1980 Glucocorticoids increase pulmonary $\beta$-adrenergic receptors in fetal rabbit. Endocrinology 107:1646

7. Dobbs LG, Mason RJ 1979 Pulmonary alveolar type II cells isolated from rats: release of phosphatidyl-choline in response to $\beta$-adrenergic stimulation. $J$ Clin Invest 63:378

8. Giannopoulos G 1980 Identification and ontogeny of $\beta$-adrenergic receptors in fetal rabbit lung. Biochem Biophys Res Commun 95:388

9. Lawson EE, Brown ER, Torday JS, Mandansky DL, Taeusch HW 1978 The effect of epinephrine on tracheal fluid flow and surfactant efflux in fetal sheep. Am Rev Respir Dis 1 18:1023

10. Liggins GL, Howie RN 1972 A controlled trial of antepartum glucocorticoid treatment for prevention of the respiratory distress syndrome in premature infants. Pediatrics 50:515

11. Mulay J, Giannopoulos G, Solomon S 1973 Corticosteroid levels in the mother and fetus of the rabbit during gestation. Endocrinology 93:1342

12. Padbury JF, Hobel CJ, Lam RW, Fisher DA 1981 Sex differences in lungs and adrenal neurosympathetic development in rabbits. Am J Obstet Gynecol 14:199

13. Smith BT, Torday JS, Giroud GSP 1973 The growth promoting effect of cortisol on human fetal lungs. Steroids 22:515

14. Walters DV, Olver RE 1978 The role of catecholamines on lung liquid absorption at birth. Pediatr Res 12:239

15. Whitsett JA, Manton MA, Darovec-Beckerman C, Adams KG, Moore JJ 1981 $\beta$-Adrenergic receptors in the developing rabbit lung. Am J Physiol (Endocrinol Metab Suppl 3) 240:E351

16. Young WS III, Kuhar MJ 1979 A new method for receptor autoradiography: $\left[{ }^{3} \mathrm{H}\right]$ opioid receptors in rat brain. Brain Res 179:255 